\title{
Psycho-social Determinants of Academic Well-being for International Students from Developed Countries who Study in Developing Countries
}

\author{
Erna Z Wiles \\ Stenden University Bali \\ ernawiles@gmail.com/erna.wiles@stenden.com
}

\begin{abstract}
Abundant research has been conducted on International students' well-being. However, little has focused on academic well-being and directed towards students from developed countries studying in developing countries as respondents. The fact that students have to live in a completely different country with different language and culture potentially creates challenges that may threaten the students' academic well-being. Thus, it will also affect their academic achievement. By using quantitative method in a form of questionnaires combined with a qualitative method in the form of a focus group, this research was conducted to construct the definition and theory of 'academic well-being', to discover the indicators of-, as well as determinants that play the most significant role in determining the students' academic well-being. Findings show that students and academic staffs have the same perception of academic well-being, which is the existence of a balance between the students' resources and the students' academic achievement, with the condition that throughout their time they are physically and psychologically healthy, have a healthy relationship with the university staff, friends and people around them, and have a future vision; with three conditions, there is a will to seek help, there is support from the staff and they live in a conducive environment.
\end{abstract}

Key words: International students, academic well-being, academic achievement

\section{INTRODUCTION}

With its motto 'Go Global Go Stenden', internationalization has been a part of Stenden University of Applied Science (SUAS). With its main campus in Leeuwarden and branches in the Netherlands like Groningen, Leeuwarden, Emmen, Mapel and Assen, in Thailand, Indonesia, Qatar, and South Africa; and with its over 11.000 students of whom 2.900 are international students of 90 different citizenships (Stenden University , 2017), it is only reasonable if the institution is committed to always keep anything related to the education international. Claimed to be the first hotel school in Europe receiving the European accreditation in internationalization (Stenden University Bali, 2017), the term "internationalization" becomes an important part of Stenden institution as it is one of three main themes that is expected to be shaping its quality along with Problem Based Learning and Applied Research (Stenden University of Applied Science, 2016). An International student in Stenden university perspective is "a student with a foreign nationality who, in case of a third-country national on the basis of a residence permit granted to this effect, desires to continue, continues or has continued his/her education at a higher education in the Netherlands". The scope has been widened into "any opportunity offered to the students to study part of their programme in any International Branch Campuses (IBC's)" (Stenden Hogeschool, 2011). For Stenden, however, internationalization is not merely about students from different countries and cultural background. Internationalization can be found in every aspect of the institution - lecturers, campuses, placements overseas, educational approaches which are problem and case based - which reflects Real World international focuses, the staff, the involvement of international institutions, internationally accepted bachelor's degree, applied research and etcetera.

It is expected that the internationalization strategy will contribute to the innovation in education, knowledge valorisation as well as to the quality of education and research (Stenden University of Applied Science, 2014). This commitment is a promise that 1) graduates will own a cosmopolitan attitude - having competency of applying their knowledge and skills obtained at school in international context with different culture and ethnicities; 2) internationally oriented programmes will serve as a preparation for graduates' future employment settings; 3) international orientation and intercultural development is accessible ensuring the opportunity within the students' own applied Sciences, within the safe learning environment of Stenden community and 4) ongoing development towards and improvement of an international and/or inter-cultural oriented curriculum is simplified.

In line with what Knight (2007a) mentioned, SUAS directs its internationalization strategy along three lines. The first one is "Internationalization at Home", in which 
international study and living climate from the local perspective is offered in all campuses. This comprises international curriculum, international disciplines, international encounters, international society, and international classes. The second one is international mobility which is a kind of encouragement to study and do the industrial placements overseas for students, staff and programmes. The programmes include among others grand tour programmes, exchange programmes, twinning programmes and internships. The last one is Internationalisation abroad through International Branch Campuses, intensive connection to global society, specific local input in the curriculum and $2+2$ or $1+3$ programmes. The policy which stipulates that to obtain the BBA Degree, it is compulsory for students of the International Branch Campuses (IBA) i.e. those who are registered in campuses other than those in the Netherlands, to take 60 European Credit points ( 60 EC's) in the Netherlands, is an example of the internationalisation commitment called $1+3$.

The primary focus, however, is the Grant Tour (GT) - a copy of a policy in the medieval era in which scholars travelled around even abroad to seek new experiences and different professors of different disciplines and ideas. The GT programmes are governed based on three principles: 1) taking advantage of local opportunities and where possible provides opportunities not readily available elsewhere in the world;2) increasing the likelihood of more students taking up GT; and 3) augmenting existing opportunities elsewhere in the Stenden University system. Grand tour students mostly take minors even though some take modules from the major. Over 50 different of minors are offered in Stenden campuses. As one of IBC's which offers four different minors, SUB receives on average 75 GT students every module (10 weeks), making it a total of 300 GT students annually.

Data from the Module Evaluations, which is conducted for every module, shows high level of satisfaction among the students with the average grades of over 7 out of 10. Lectures and lecturers are graded on average 7 . Negative feedback is mostly about the module assignments which is felt to be big and challenging as students have to do it in groups. Some express the difficulties in doing the assignment because each member of the group does not have the same work ethics. There are always incidents in each module ranging from various health issues, (traffic) accidents, to thefts and robberies. Health problems, from the mild ones like Bali Bally, dengue, fever to the serious ones like appendicitis are the biggest contributor to absenteeism. Despite all the above issues, the level of achievement is quite high i.e. $90 \%$ for Event Management and $80 \%$ respectively for Marketing Management in Asia and Spa Business and Strategy making it on average between 2013-2016 was 83\%. From the preliminary research, it was discovered that most challenges are the fact that there are so many temptations in Bali, ranging from night lives, alcohol, beautiful places in the surrounding, so enticing that students spend most nights and weekends away, ignoring the fact that they have to study. This has become worse as social solidarity forces them to go along with friends.

This high percentage of failing, is also suspected as an indicator of the low level of students' academic wellbeing and it has become SUB's agenda to ensure the students' academic well-being and guaranteeing their academic achievement. What is academic well-being, has there been awareness among students and academic staff, and what can be done if it is proven that the failure is the results of low level of academic well-being?

\section{LITERATURE REVIEW}

The term internationalization is nothing new, it has been existing for centuries and was initially used mostly on political science and governmental relations and in the later stage the scope is getting narrower into just the higher education sector. Internationalization in the education sector only started to gain its popularity in the 1980s.

Internationalization itself is defined as "the process of integrating an international, intercultural, or global dimension into the purpose, functions or delivery of postsecondary education" (Knight, 2008, p. 21). Considered to be having a narrow scope, Hawawini (2011, p. 5) proposed an alternative definition "The internationalization of higher education institutions is the process of integrating the institution and its key stakeholders - its students, faculties, and staff - into a globalizing world" and it is claimed that not only does the definition go beyond dimensions of teaching, research and service but also demands of the alteration of current structures, operating modes and mind-sets, so as for the institutions to be to get involved and contribute to the shaping of the emerging global knowledge and learning network.

Other than that, internationalization is differentiated into 1) international at home - more about curriculum oriented, which focuses on any curriculum-oriented and concerns with any activities related to global understanding and inter-cultural skills; and 2) international abroad - any forms of education across border (Knight, 2008).

The Organization for Economic Co-operation and Development (OECD) reported that, within its OECD members of 35 countries, $6 \%$ of the students enrolled in tertiary education in 2014 were International students (OECD, 2016). The number increased by $50 \%$ from 2005 to 2012 , whereas the growth of $5 \%$ was recorded between 2013 and 2014, making OECD countries hosting on average three International students for each citizen who 
was taking their studies outside of their respective countries of origin (OECD, 2015).

According to (Altbach \& Knight, 2007) and (Knight, 2008), due to its benefit, the international education inspired countries to set up tertiary education programmes to attract international students. International students contribute $\$ 35.8$ billion to the US economy in 2015 (IIE, 2016), $£ 1.6$ billion in France in 2014-2015 (Smith, 2015), £25.8 billion in gross output in the UK in 2014-2015, (Smith, 2017) and Australia is expecting \$ 19.7 billion at the end of 2016 (Hare, 2016). No wonder internationalization has become a lucrative commodity from some countries. Unfortunately, there are no equality of the distribution in this case. The annual report by OECD shows 1.3 million international students were enrolled in masters and doctoral programmes in OECD countries (OECD, 2016). International students pursue their master's and doctoral degree in advanced countries like The United States (26\%), The United Kingdom (15\%), Germany (10\%), France (11\%), and Australia $(8 \%)$. These students are mostly from Asia (53\%) comprising China (22\%), India, Japan and Oceania. Only few was the number of students from developed countries studying in developing countries.

The main considerations when choosing the country can be categorized into 1) Language of instruction - most candidates would choose a country of which the language is mostly spoken and read globally, takes, for instance English; 2) The quality of the program; 3) Tuition fee; and 4) Immigration Policy (OECD, 2016). Other reasons such as recognition of the degree, study workload, future opportunities to work in the home country, cultural aspiration, etcetera also influence the decision to enrol.

Studying abroad is not less challenging when compared to studying at home. Very often, the students' well-being is at stake. Studies from varieties of journals and research reports show that challenges faced by international students can be categorised into two which are academic-related and non-academic related (Yeoh, Le, \& Doan, 2013). Most academic issues persist because of language barriers, mostly for those coming from nonEnglish speaking countries. The impact can be quite serious as this does not only influence the students' academic performance but also their social life. Very often students feel isolated. The lack of language proficiency also affects the students' self-efficacy, subsequently may hinder students from gaining knowledge that can be used to assist them in adjusting themselves to the new environment. The second big issue is related to adapting to new learning style as it has become a common knowledge that Asians employs different learning approaches when compared to Western educational institution, in which Asian culture is more teacher-centred whereas western education system requires students to be more independent, be more engaged in the process as well as be more initiative. Mori (2000) added that the relationships between the students and the teachers, academic credits, grading scales, class attendance, class discussions and class types as well as the frequency of quizzes, examinations, presentations, assignments and plagiarism potentially also create problems.

Non-academic challenges can be categorised into 1) psychological/mental health issues, 2) physical Issues, 3) social Issues, and 4) financial issues. The first and foremost difficulty psychologically is mostly culture shock, which is defined as "a negative state generated by being in an unfamiliar cultural environment" Other issues are homesickness, loneliness, depression and anxiety (Rajapaksa \& Dundes, 2003). Other than that, different climate and living condition including the adaptation to the new diet are proven to be causing problems such as feelings of disorientation, confusion and spiritual displacement. Physical issues persist because of fatigue, lack of nutrition and other health-related risk-taking behaviour such as unsafe sex activities which very often result in unwanted pregnancies and irresponsible alcohol consumption, as well as gambling (for male students) and this these issues may lead to taking own lives (Government of South Australia, 2013). Social issues are often rooted from lack of language proficiency, cultural differences and heavy load from the studies and are proven to be the cause the reluctance of socializing and doing leisure activities (Alghamdi \& Otte, 2016). Making it worse, Constantine, Anderson, Berkel, Caldwell, \& Utsey (2005) claimed that very often prejudices, stereotypes, racial discriminations (skin colour-based) as well as neo-racism (culture-base) hinder the international students to build a healthy relationship with the hostcountry citizens; and these affect the students' safety and security. According the Forbes-Mewett \& Sawyer (2011), very often students become the victims of exploitation and violence. Financial issues persist because most international students generally must pay higher tuition fees compared to local students. Exchange rates are also inauspicious as a small amount of money in the country where they study can be a large sum in their country (Banjong, 2015).

According to Tseng \& Newton (2002) there are eight ways to help international students pass their adjustment phase, which are forming relationships, seeking assistance, increasing English proficiency, improving social and cultural communications, building relationships with faculty members, identifying themselves and others, letting go issues and expanding their view to the world. (Tomich, McWhirter, \& Darcy, 2003) suggested other solutions: 1) Hire staff who are not only qualified but also well-suited for the positions in International Student Offices; 2) Provide intercultural and multicultural communication programs/services; 3) Plan a host-family program for newly-arrived international students; 4) Offer courses that would encourage students to learn different cultures; 5) Encourage student exchange and study abroad programs; 6) Engage international students in student organisations 
not only of their own culture, but of other cultures as well; 7) Offer ESL support for international students; 8) Last but not the least, listen to what an international student has to say regarding their problems without being defensive and accusatory.

Psychological issue can also be reduced by providing counselling. Psychoeducational behavioural group with the aim of assisting students to obtain their confidence, build interpersonal skills and obtain satisfactory academic achievement, while at the same time can still maintain their cultural identity, has been proven to be effective (Smith \& Khawaja, 2011). It is important that the counsellors guide the students into taking positive coping strategies (Olivas \& Li, 2006); thus, counsellors also need to have multi-cultural competency and be culturally responsive throughout the sessions. Secondly, the counsellors need to raise the students' awareness on the necessity of help-seeking, as it is proven that, due to the cultural backgrounds, there might be reluctance among the students to disclose their problems to strangers. In this case, helping approaches and methods, which among others are less formal type of counsellingtype of presentations, discussions, regular meetings, providing academic and career planning assistance need to be utilized. Prevention services like mentoring programmes, providing referral services, setting up groups to enhance their academic and study skills, are also highly suggested. Providing new students orientation programmes in which cultural differences are addressed is also essential. Financial issues can be prevented by, providing financial survival guides such as distributing manuals containing information regarding financial matters (UK Council for International Student Affairs, 2008).

There has been vast research conducted on International Students, unfortunately, most are students from developing countries who take tertiary education in developed countries. Little was it about those from developed countries who study in developing countries. This has raised an issue as to whether these students face the same or similar challenges as their counterparts. Research was carried out with the purpose to identify problems that may jeopardise the students' academic well-being. Specific purposes are 1) constructing the definition of academic well-being, 2) discovering academic well-being indicators, 3) finding out aspects contributing to academic well-being, 4) seeing factors contributing failures and 5) seeking possible solutions to problems faced by students so as they can achieve their well-being. All findings are expected to be able to be used as recommendations for Stenden University Bali to design a specific policy to guarantee the students' academic well-being.

\section{RESEARCH METHODS}

Aside from data gathered through desk research (documents at Stenden University Bali), qualitative data collection was employed by making use of a questionnaire and a focus group. The questionnaire, consisting of 5 open-ended questions, was for the first population - grand tour students Stenden University Bali, module 3, 2016-17 and the focus group was for the second population - the academic team consisting of one academic coordinators, seven module coordinators, a counsellor and the academic assistant. All of the academic team members except the academic assistance also have the role as tutors and lectures of different subjects. Questions for both are 1) What is academic well-being to you?; 2) What are the indicators of wellbeing? (You see students academically well-being when....?; 3) What factors influence academic wellbeing? 4) What could possibly jeopardize your study? Please list any problems which you think may cause students fail to achieve their best. 5) How do you think those problems can be avoided? Please list your suggestions. Data obtained was analysed by using Excel and NVivo. To ensure confidentiality letters of consent were provided for both populations.

\section{RESULTS}

\section{Demographic Data}

Data taken from 2013-2017 shows that annually, SUB hosts on average 270 students, of whom mostly took module Event management (EM), followed respectively by Marketing Management in Asia (MMA), and Spa Business Strategy (SBS). Most students are of Dutch nationalities followed by German, Romanian, South African, Bulgarian, and the rest are of different nationalities. The percentage of students' gender is $75 \%$ female and $25 \%$ males.

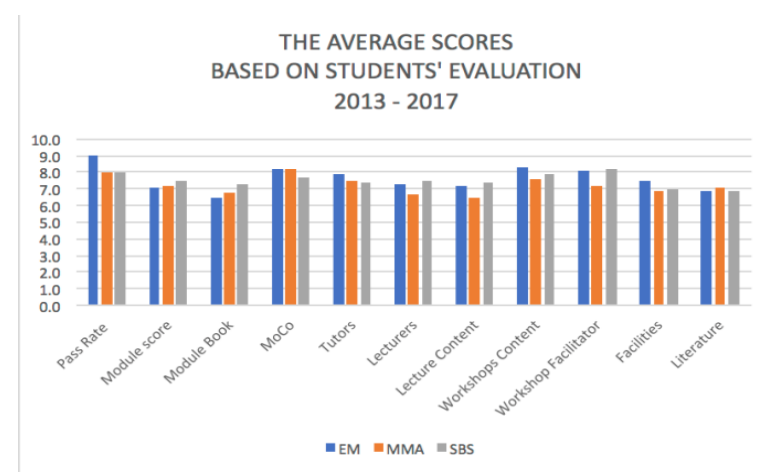

Figure 1. Scores from the module evaluation

As can be seen in figure 1 , the module evaluations conducted at the end of each module show the students' high appreciation, with most aspects of educational 
programs such as the overall modules, the module books, the module coordinators, the tutors, the lecturers, the lecture content, the workshop facilitators scored between 7-8 on a scale of 1-10. It is worth pointed out that the passing rate is still quite high, which is $90 \%$ for EM and $80 \%$ respectively for MMA and SBS.

\section{Aspects Constituting Academic Well-being}

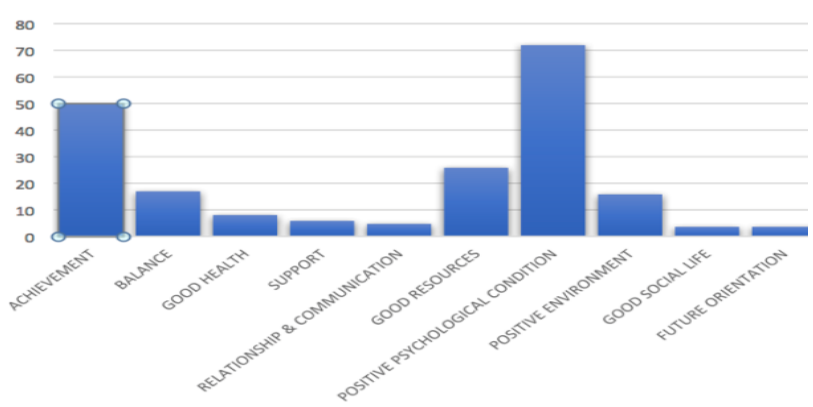

Figure 2. Students' perspective on aspects constituting well-being.

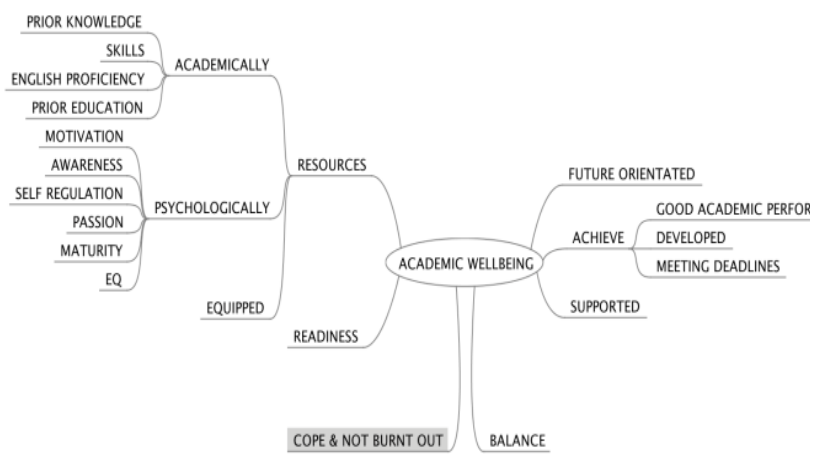

Figure 3. Academic staff' perspective on aspects constituting well-being

Figure 2 shows that the biggest contributor of students' academic well-being is positive psychological condition, followed respectively by achievement, good resources, positive environment, good health, various supports from the institution such as from the module coordinator, the coach, the psychologist and the psychiatrist, good relationships and communication with the module coordinator, tutor, lecturers, coach, good social life. Another important aspect is the existence of "balance" between the resources that the students have with the challenges they face and the academic demand. Other than that, academic well-being is also determined by whether or not students have future orientation. Figure 3 , on the other hand, shows that academic well-being comprises of the balance between resources and readiness and achievement and future orientation with the condition students will only cope if there are any support available.

\section{Academic Achievement}

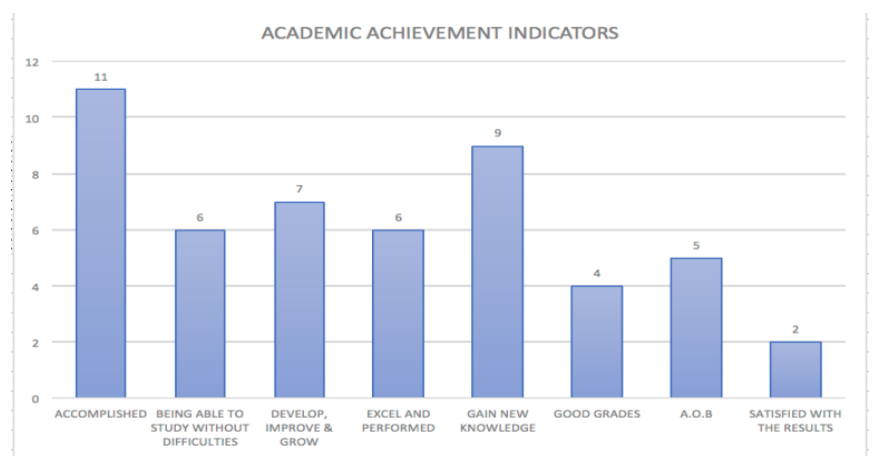

Figure 4. Academic achievement indicators

Students are perceived to have high achievement if they can accomplish all the assignments on time. One of the requirements is that they have to be able to study without any difficulties. Achievement also means the ability to develop and grow as expected, excel and perform throughout the module and obtain good grades. Moreover, students need to feel satisfied with the results.

\section{Academic well-being indicators}

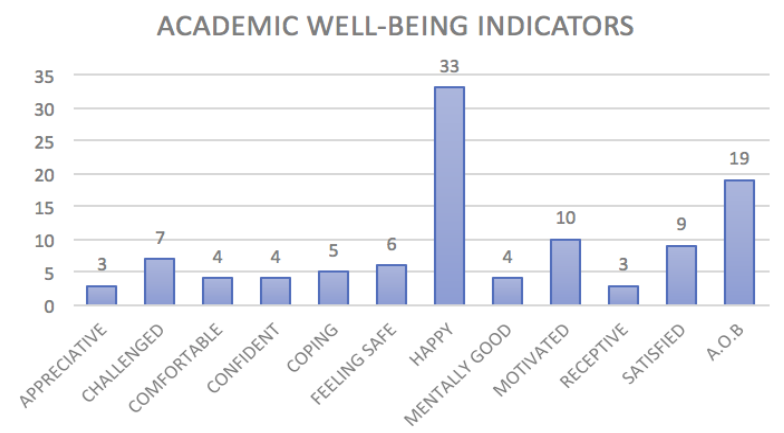

Figure 5. Academic well-being indicators

Figure 5 shows that students are academically well-being when there are such indicators such as being happy, motivated, satisfied, challenged; feeling safe, can cope with difficulties and problems, confident, mentally good, receptive and appreciative.

\section{Factors determining academic achievement}

There are two factors that can determine the students' achievement, namely, external and internal factors. It is also important to see whether there is a balance between them. The most influential external factors are from the institution which comprise of the quality of the relationships and communications between the students and the people in charge at the institution, the family and friends, the facilities and the resources, the educational system, the existence of support and assistance and staff professionalism. Other external factors are the conduciveness of the school environment and lodging and various cultural issues. The internal factor that plays 
the most significant role in determining academic wellbeing is the students' psychological state, followed by physical health, the ownership of personal resources, emotional intelligence, the existence of motivation, students positive attitude, right-fit expectation and interest.

\section{Factors that may generate Failure}

Findings also show that failure can be caused by external factors which mostly came from the institution such as the quality of relationship and communication between the students and the people in charge, followed by the assignments complexity and the level of difficulty, facilities and resources, staff professionalism, the structure and the clarity of the module, the grading system and the high expectation from the module coordinator. One factor that has a big role in determining the failure is whether the environment where the students live support is conducive enough to study. Other than that, family issues, which among others are parents' divorce, relatives' death, family members' sicknesses, very often force the students to go home to their countries before the module is over. Last but not least is financial matter. Very often students overspend. Internal factors determining the failure are personal (50\%), psychological (36\%) and physical (14\%). The inability to resist friends' invitations for parties and trips in and outside Bali has become the number one cause of failure, followed by personal problems, bad planning and preparation and learning disabilities. There are other issues like accidents, casualties, bad attitude and behaviour, bullying, laziness, being caught in legal issues etcetera but the percentage is not high.

The biggest number of psychological factors determining the failure is the lack of motivation or demotivation, followed by stress and depression and homesickness, addiction, fear and safety issues and unhappiness. Whereas physical factors among others are various illnesses or sicknesses like dengue, appendicitis, flu, cold and cough.

\section{Proposed Solutions}

Students have actually proposed some solutions to avoid the deteriorating of students' well-being and to ensure that students can finalize the module without failing any units. Students consider that adjusting the education system is the number one priority. The priority should be on adjusting the structures of the module and the assignments, followed by giving support and assistance to the students, increasing the staff professionalism, providing needed facilities, reducing the rules and the regulations lenience, more cultural orientation and providing conducive environment, be it at the campus or at the hotel where the students stay. Other than that, students need to have personal effort to help themselves and to avoid having their well-being disturbed. In this case, students expect that they make a better planning and do enough preparation, increase their emotional intelligence as well as self-awareness, socialize in a positive manner, do enough measures prevent incidents that might jeopardise their well-being and start to act with full responsibility. Raising awareness to seek help is also a must and there should be balance between the demand - in this case the assignments and the resources that the students have.

\section{DISCUSSION}

Students' academic well-being is the key to ensure good academic achievement. Thus, it should become the number one priority for all the stakeholders involved in an educational institution. First of all, academic wellbeing should be clearly defined. The limited number of previous research findings makes it difficult to establish a general and acceptable understanding on the definitions. It is only ideal if there is a uniformity between students and academic staff's perception and expectation regarding academic well-being.

Finding shows that there are similarities between students' and staff's perceptions. Students define academic well-being as "the balance between sources owned and their academic achievement, and when throughout their time in the institution, students are healthy physically and psychologically, have good social relationships with the academic staff, friends and the people where they live, and have future visions; with the conditions, there is assistance and support from the staff and they live in a conducive environment". The academic staff, on the other hand, defines academic well-being as "the balance between the academic and psychological sources owned by the students with their academic achievement with conditions that students are in the 'right fit', feel happy, are not burnout and can cope with and solve problem as well as own a future vision". Firstly, both contains the words 'balance' and 'sources' and "future vision" which are similar to the definition of wellbeing in general coined by (Dodge et al, 2012). Secondly, it involves physical and psychological health. Thirdly, it is dependent on the school community, friends and people living around the students. Lastly, it also concerns future visions which are in line with the goals. What is lacking is the understanding that academic well-being is actually the well-being related to educational context and places the school as the central factor in students' lives (Korhonen, Linnanmäki, \& Aunio, 2014). Students are considered to be academically well-being if they are happy, motivated, satisfied, feel challenged, feel safe, can cope with difficulties and problems, confident, mentally good, receptive and appreciative. This is slightly different from the indicators stated by (Opdenakker \& Van Damme, 2000) in which students are academically wellbeing if they can integrate socially at school, have good relationships with the teachers, have interest to school 
tasks, are motivated in doing all tasks and homework and attentive when in class.

Findings also show that factors determining academic well-being can be classified into two i.e. internal such as students physical and psychological health, resources such previous educational background, expectation, emotional intelligence, motivation, behaviour and attitude and interest; and external such as students' relationship with the academic staff - lecturers, module coordinators, and study coaches, facilities, educational system, environment conduciveness, assistance and supports, staff professionalism, family and financial sources. Some are similar to those stated by (Touminen-Soini, Salmela-Aro, \& Niemivirta, 2012), (Korhonen, 2016), (Esteve, 2008) and (DeGarmo \& Martinez Jr., 2006), in which factors determining academic well-being among others are goal achievement orientation, grades, school burnout, school engagement, satisfaction to the choice of the education, self-esteem, self-efficacy, self-concept, perception on learning difficulties, and social support from the university, friends and parents. Other than that, one of the keys to academic well-being is the ability to adapt to the new learning environment. What is missing is the will to seek help, coping, resilience and the ability to bounce back from difficulties as stated by Bernard (2004), (Luthar, Cicchetti, \& Becker (2000), Howard \& Johnson (2000) and Johnson, Dinsmore, \& Hof (2011).

Possible issues that can hinder students from achieving the expected academic well-being can be categorized into three factors. They are external, personal and psychological factors. External factors are mostly related to the educational issues such as the relationships with the academic staff which hinders the students seeking assistance when facing problems; big size of assignments which mostly are group assignment of which friends' unprofessionalism very often create frictions and group dynamic; facilities and resources such as internet connections and literature; staff professionalism, structure and clarity of the module, unconducive environment, and grading systems. Other than that, family issues such as divorce, health and death very often force the students to terminate their education to fly home; even though students may still have exam in the Netherlands. This still somewhat delays the process of finalizing the module. Financial issues, which mostly are related to students' inability to manage as due to the temptations students excessively spend their money on alcohol and travelling, persist mostly closer to the end of the module. The discrepancies between the academic's expectation and the students' wrong expectation they bring from home, in which for students, taking minor at Stenden University Bali means less assignments and spending time in clubs and beaches. This has created a perception that the management has set a very high expectation to the students. This is not the case because the management of Stenden University merely commits to maintaining the quality, which means implementing and adhering to the Teaching and Examination Regulations.

Personal issues range from solidarity and subsequently inability to decline friends' influence to go partying and spending weekends in different islands; personal problems like love life, limited amount of planning and preparation prior to their departure and some learning disabilities like dyslexia and dyscalculia. Psychological issues are mostly the declining of the motivation and homesickness, especially those who have taken a prerequisite module in Thailand. Others are stress and depression, addiction, fear and safety issues and the loss of interest.

Other types of issues such as physical problems related to fatigue and lack of nutrition as well as unsafe sex as reported by Government of South Australia (2013) were hardly found as most cases recorded are related only to the new diet, dengue and road accidents. Social issues rooted from the lack of Indonesian language proficiency and the reluctant to mingle with locals as mentioned by Alghamdi \& Otte (2016); prejudice, stereotypes and racial discrimination as stipulated by Constantine et al, (2005) and exploitations as well as violence as stated by Forbes-Mewett \& Sawyer (2011) never happen. Students can always communicate with the locals. Most Balinese, as Bali is the number one tourist destination, can speak English. Students also find Indonesian to be friendly, hospitable and receptive. The never experience any racism nor stereotyping. In certain time students even feel the privilege of being treated as honourable guests. That is why issues such as culture shock and adjustment/adaptation, never happens. Contrary to what Paltridge et al, (2012) mentioned, students feel they can integrate socially, culturally and economically quite easily.

It can be concluded that there is a big similarity between the students' and academic staff's perception regarding the definition of academic well-being. It is all about balance between resources that the students and the good academic achievement of which conditions are set, which are good relationship between students and staff, conducive living and academic environment as well as the existence of assistance and support. This uniform vision allows easier measures to be taken in order to improve students' academic well-being and to reduce the percentage of failure. Students and staff can point out indicators and aspects of well-being, and this has made it easier to identify when students' academic well-being is disrupted. Further to that students can also identify issues which can cause failures thus prevention can be done. As for obstacles faced by International students coming from developed countries taking education in developing countries are proven to be different from their counterparts.

\section{CONCLUSIONS AND SUGGESTIONS}


To minimize the impact of those aforementioned issues, students have proposed some solutions. The first solution is directed towards the university. There should be an adjustment in the education system. The first priority is to have a more structured module and much less burdening assignments allowing students to work with lesser number of group member. Assistance and support throughout the students' time needs to be improved. Staff professionalism is expected to be maintained. Facilities, which in this case are internet connection has to be faster and more literature needs to be added. Students expect to have less stricter rules and regulations. Cultural orientation should be given prior to the starting of the module and the educational and living environment need to be made more conducive guaranteeing students to be able to study without any meaningful disturbance.

Some of these proposals have actually been done in Stenden university, takes an example providing cultural orientation, improving the structure of the education, providing support, assistance psychological counselling, etcetera. Unfortunately, some seem to be impossible, takes for instance improving the internet connection and imposing stricter rules and regulations.

Other recommendations are directed towards the students themselves, which are improving the quality of relationship and communication with the academic staff, raising their effort to be emotionally more intelligence, doing better preparations, improving their selfawareness, socializing with in a positive way, taking measure to prevent unwanted problems and be more responsible. It is expected that students are more proactive in seeking help and assistance once they sense they have problems. More importantly, there should be balances between the demand - in this case the assignments and the resources that the sources that students have, between social life and academic matters, and between fun and seriousness.

Further research with detailed questions and bigger size of population is suggested, in order the gain deeper insights on academic well-being.

\section{REFERENCE}

Alghamdi, H., \& Otte, S. (2016). Challenges and Benefits of Study Abroad. International Journal of Humanities and Social Science, 6(5), 16-22.

Altbach, P. (1998). Comparative Higher Education: Knowledge, The University ad Development. Wesport, Connecticut, The USA: Greenwood Publishing Company.

Banjong, D. (2015). International Students' Enhanched Academic Performance: Effect of Campus Resources. Journal of International Students, 5(2), 132-142.
Bernard, B. (2004). Reciliency: What We Have Learned. San Francisco, CA, The USA: WestEd.

Constantine, M., Anderson, G., Berkel, L., Caldwell, L., \& Utsey, S. (2005). Examining the cultural adjustment experiences of African international college students: A Qualitative Analysis. Journal of Counseling Psychology, 52, 57-66.

DeGarmo, D., \& Martinez Jr., C. (2006). A Culturally Informed Model of Academic Well-Being for Latino Youth: The Importance of Discriminatory Experience and Social Support. Family Relations, 55, 267-278.

Dodge, R., Daly, A. P., Huyton, J., \& Sanders, L. D. (2012). The challenge of defining well-being. International Journal of Well-being, 2(3), 222 - 235.

Esteve, E. (2008). Well-being and Performance in Academic Settings: The Predicting Role of Self-efficacy. The Spanish Ministry of Science and Technology, The Department of Social Psychology at Universitat Jaume I in Castellón. Castello de la Plana: Universitat Jaume I.

Forbes-Mewett, H., \& Sawyer, A. (2011). Mental Health Issues amongst International Students in Australia: Perspectives from Professionals at the Coal-face. Australian Sociological Association (pp. 1-19). Newcastle, Australia: Tasa: The Australian Sociological Association.

Government of South Australia. (2013). International Student Health and Well-being: A Health Lens Project Supporting South Australian Vocational Education \& Training Sector International Students. International Student Health and Well-being Health Lens project, DFEEST, MSA and DHA, DFEEST, MSA and DHA, Adelaide, Australia

Hare, J. (2016, May 6). Overseas students contribute record $\$ 19.7 \mathrm{bn}$ to economy. The Weekend Australian.

Hawawini, G. (2011). The Internationalization of Higher Education Institutions: A critical Review and a Radical Proposal. The Business School for the World. Singapore: INSEAD.

Howard, S., \& Johnson, B. (2000). Resilient and Non-Resilient Behavior in Adolescents. Australian Institute of Criminology, 183, 1-6.

IIE. (2016). Open Doors Data - Special Reports: Economic Impact of International Students. Institute of International Education: Opening Minds to the World. New York, The USA: Institute of International Education, Inc.

Knight, J. (2007a). Crossborder Tertiary Education: An Introduction". Crossborder Tertiary Education: A Way Towards Capacity Development, 21-46.

Knight, J. (2008). The Changing World of Internalization (Vol. 13). Rotterdam, The Netherlands: Sense Publisher.

Korhonen, J. (2016). Learning Difficulties, academic well-being and educational pathways among adolescent students. Åbo Akademi University, Vasa, Findland, Faculty of Education and Welfare Studies. Turku, Findland: Painosalama Oy .

Korhonen, J., Linnanmäki, K., \& Aunio, P. (2014). Learning difficulties, academic well-being and educational dropout: A person-centres approach. Learning and Individual Differences, 31, 1-10.

Luthar, S., Cicchetti, D., \& Becker, B. (2000). The Construct of Resilience: A Critical Evaluation and Guidelines for Future Work. Child Development, 71(3), 543-562. 
Mori, S. (2000). Addressing the mental health concerns of international students. Journal of Counseling and Development, 78(2), 137-44.

OECD. (2015). Education at a Glance 2015: OECD Indicator. The Organization for Economic Cooperation and Development. Paris: OECD Publishing.

OECD. (2016a). Education at a Glance Interim Report: Update of Employment and Educational Attainment Indicators. Organisation for Economic Co-operation and Development, The Secretary General of the OECD. Paris: OECD: Better Policies for Better Lives.

OECD. (2016b). Global Competency for an Inclusive World. Organization for Economic Co-operation and Development, Programme for International Student Assessment. Paris: OECD: Better Policies for Better Lives.

Olivas, M., \& Li, C. (2006). Understanding Stressor of International Students in Higher Education: What College Counselors ans Personnel Need to Know. Journal of Instructional Psychology, 33(3), 217-222.

Opdenakker, M., \& Van Damme, J. (2000). Effects of Schools, Teaching Staff and Classes on Achievement and Well-Being in Secondary Education: Similarities and Differences Between School Outcomes. School Effectiveness \& School Improvement. School Effectiveness \& School Improvement - An International Journal of Research, Policy and Practice, 11(2), 165-196.

Paltridge, T., Mayson, S., \& Schapper, J. (2012). Covering the Gap: Social Inclussion, International Students and the Role of Local Government. Australian Universities' Review, 54(2), 29-39.

Rajapaksa, S., \& Dundes, L. (2003). It's a Long Eay Home: International Student Adjustment to Living in the United States. Journal of College Student Retention, $4(1), 15-28$.

Smith, B. (2015, January 5). International students contribute $€ 1.6 \mathrm{bn}$ to French economy. The PIE News: News and business analysis for Professionals in International Education.

Smith, B. (2017, March 6). International students worth more than $£ 25$ billion to UK economy. The Pie News: News and business analysis for professionals in International Education.

Smith, R., \& Khawaja, N. (2011). A review of the acculturation experiences of international students. International Journal of Intercultural Relations, 35, 699-713.

Stenden Hogeschool - University of Applied Sciences. (2016). Mater of Arts Degree Program: International Hospitality and Service Management - Teaching and Examination Regulation - Cohort 2016. Teaching \& Examination Regulations MA IHSM 2016. Leeuwarden, The Netherlands: Stenden.

Stenden Hogeschool. (2011, July). Bachelor Degree programme Hotel Management Associate Degree programme Hotel Management. The Netherlands: Netherlands Quality Agency.

Stenden University. (2017). Stenden University of Applied Science. Retrieved from https://stenden.com/exchangetostenden/

Stenden University Bali. (2017). International Hospitality Management.

Tomich, P., McWhirter, J., \& Darcy, M. (2003). Personality and international students' adaptation experience. International Education, 33(1), 22-39.
Touminen-Soini, H., Salmela-Aro, K., \& Niemivirta, M. (2012). Achievement goal orientations and academic wellbeing across the transition to upper secondary education. Learning and Individual Differences, 22, 290-305.

Tseng, W., \& Newton, F. (2002). International Students' Strategies for Well-being. College Student Journal, 36(4), 591-597.

UK Council for International Student Affairs. (2008). Students in financial hardship: an adviser's guide. London, The UK: UKCISA.

Yeoh, J., Le, T., \& Doan, T. (2013). Student Studying in an Australia University Context. In T. Le, \& Q. Le, Conducting Research in a Changing and Challenging World (pp. 303-309). Hauppauge, NY, The USA: Nova Science Publishers Inc. 